\title{
Sistem Kontrol Pintu Pagar Rumah Berbasis Arduino dengan Koneksi Nirkabel Bluetooth pada Smartphone Android
}

\author{
Hadian Satria Utama ${ }^{1}$ \\ Program Studi Teknik Elektro Universitas Tarumanagara \\ Email: hadianu@ft.untar.ac.id \\ Jullio Setiawan ${ }^{1}$ \\ Program Studi Teknik Elektro Universitas Tarumanagara \\ Pono Budi Mardjoko ${ }^{2}$ \\ Universitas Pelita Harapan \\ ponobm@yahoo.com
}

\begin{abstract}
The gate of the house has a very important role in everyday life, especially as a house with the road limits. The gate used in Indonesia on average has a work method pushed or pulled to close or open. To ease the burden of users, then built a remote gate control system. Control of the gate can be done using an Android smartphone as the interface. By using Bluetooth connections and programs on Android smartphones, users can simply control open or close the gate with just a touch. The designed gate can also be locked using an electric lock, so Android smartphone users can lock and unlock the fence. The system is also equipped with an object sensor that can resist the movement of the gate so as not to close when the object from the direction of the house wants to leave the house. Each key function and fencing motion can also be done without a Bluetooth connection that is by using a manual button module that has been designed using a microcontroller. Any function that can be done by programmable gate using a microcontroller is Arduino Mega. The results achieved in testing this system is the gate can be controlled remotely using a Bluetooth connection to open/close the gate, as well as lock/unlock the gate. In addition, the gate can be locked and unlocked remotely using the program on Android smartphones, besides that each function can be done without Bluetooth connection using manual button.
\end{abstract}

Keywords: Android; Bluetooth; gate control; home gate.

\begin{abstract}
ABSTRAK: Pintu pagar rumah memiliki peran yang sangat penting dalam kehidupan sehari-hari terutama sebagai pembatas rumah dengan jalan. Pintu pagar yang digunakan di Indonesia rata-rata memiliki cara kerja didorong atau ditarik untuk menutup atau membuka. Untuk meringankan beban pengguna, maka dibangun sebuah sistem pengontrolan pintu pagar jarak jauh. Pengontrolan pintu pagar dapat dilakukan dengan menggunakan sebuah smartphone Android sebagai antar muka. Dengan menggunakan koneksi Bluetooth dan program pada smartphone Android maka pengguna dengan mudahnya melakukan kontrol buka atau tutup pintu pagar dengan hanya sentuhan. Pintu pagar yang dirancang juga dapat dikunci dengan menggunakan sebuah kunci elektrik, sehingga pengguna smartphone Android dapat mengunci dan membuka kunci pagar. Sistem ini juga dilengkapi dengan sebuah sensor obyek yang dapat menahan gerakan pintu pagar agar tidak menutup ketika obyek dari arah dalam rumah ingin keluar rumah. Tiap fungsi kunci dan gerak pagar juga dapat dilakukan tanpa koneksi Bluetooth yaitu dengan menggunakan modul tombol manual yang telah dirancang menggunakan mikrokontroler. Setiap fungsi yang dapat dilakukan oleh pintu pagar diprogram menggunakan sebuah mikrokontroler yaitu Arduino Mega. Hasil yang dicapai pada pengujian sistem ini adalah pintu pagar dapat dikontrol dari jarak jauh menggunakan koneksi Bluetooth untuk melakukan buka/tutup pintu pagar, serta kunci/buka kunci pintu pagar. Selain itu pintu pagar dapat dikunci dan buka kunci dari jarak jauh menggunakan program pada smartphone Android, selain itu tiap fungsi tersebut dapat dilakukan tanpa koneksi Bluetooth dengan menggunakan tombol manual.
\end{abstract}

Kata kunci: Bluetooth; Android; pintu pagar rumah; kontrol pintu pagar.

\section{PENDAHULUAN}

$\mathrm{S}$ etiap keluarga yang tinggal dalam sebuah rumah memiliki akifitas berbeda-beda, baik aktifitas di dalam rumah maupun di luar rumah. Aktifitas yang dapat dilakukan di dalam rumah seperti memasak, menyapu, membersihkan kendaraan, dan lain lain. Aktifitas di luar rumah dapat berupa membuka pintu pagar, membersihkan halaman, memotong rumput halaman, dan masih banyak lagi. Aktifitas membuka/menutup pintu pagar digunakan untuk masuk/keluar tamu rumah dan anggota keluarga rumah.

Pintu pagar adalah sebuah alat yang berfungsi juga sebagai pagar untuk menjaga keamanan isi rumah dari bahaya-bahaya kriminal dan kecelakaan di depan rumah. Bahaya kriminal dapat berupa masuknya pencuri, percobaan sadap pesawat telepon, dan lain-lain.

Pintu pagar mempunyai bahan yang bervariasi dimulai dari silinder besi kosong, dan besi berisi. Pintu pagar yang menggunakan besi berisi mempunyai bobot paling berat untuk digerakkan di antara semua jenis bahan. Pada segi ketahanan pintu pagar, jenis besi berisi yang memiliki ketahanan akan benturan, sedangkan bahan pada besi kosong unggul pada keringanan bagi pasien itu sendiri. Pada

\footnotetext{
${ }^{1}$ Program Studi Teknik Elektro Universitas Tarumanagara

${ }^{2}$ Universitas Pelita Harapan
} 
beberapa rumah sakit, pemanfaatan kabel masih banyak digunakan untuk sistem pemanggil suster. Penggunaan kabel juga dapat memberikan masalah, seperti data yang tidak dapat dikirimkan dengan baik akibat putusnya kabel dan kabel yang tidak terpasang dengan baik.

Pintu pagar pada Gambar 1 memiliki 2 buah daun pintu pagar, 2 buah tombol untuk buka dan tutup pintu pagar, dan 2 buah motor direct current (DC) yang ditunjukkan oleh kotak merah pada gambar. Tombol kontrol yang digunakan dihubungkan langsung pada masing motor DC. Motor DC digunakan untuk menarik daun pintu pagar masing-masing ketika tombol pengendali ditekan, sehingga pintu pagar terbuka dan mobil dan motor dapat melewatinya. Menutup pintu pagar menggunakan tombol tutup sehingga motor DC berbalik arah dan 2 daun pintu pagar saling mendekat dan pintu pagar tertutup.

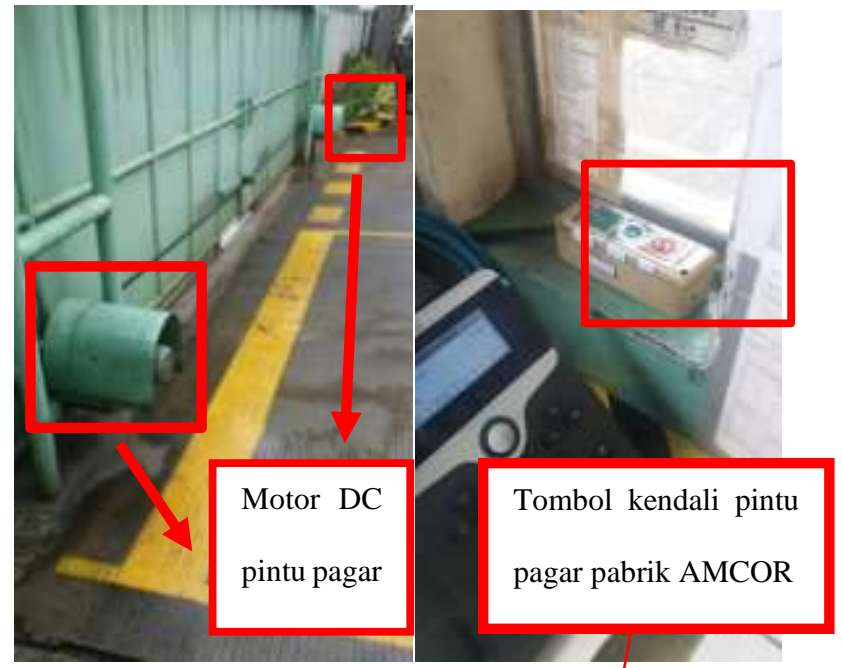

- Gambar 1. Hasil Survei Pengamatan/Pintu Pagar Pabrik AMCOR

Pintu pagar pada Gambar 1 memiliki 2 buah daun pintu pagar, 2 buah tombol untuk buka dan tutup pintu pagar, dan 2 buah motor direct current (DC) yang ditunjukan oleh kotak merah pada gambar. Tombol kontrol yang digunakan dihubungkan langsung pada masing motor DC. Motor DC digunakan untuk menarik daun pintu pagar masing-masing ketika tombol pengendali ditekan, sehingga pintu pagar terbuka dan mobil dan motor dapat melewatinya. Menutup pintu pagar menggunakan tombol tutup sehingga motor DC berbalik arah dan 2 daun pintu pagar saling mendekat dan pintu pagar tertutup.

Survei jurnal dilakukan dengan membaca jurnal yang berjudul "Perancangan dan Implementasi Pengendali Pintu Pagar Otomatis Berbasis Arduino" dari hasil karya Wilfrid Sahputra Girsang dan Fakhruddin Rizal Batubara yang berasal dari Falkutas Teknik Universitas Sumatera Utara (USU) jurusan Teknik Elektro.

Pada jurnal tersebut, dikatakan bahwa alat yang dirancang memiliki tiga sarana untuk membuka pintu pagar yaitu menggunakan Radio Frequency Identification (RFId), website melalui internet, dan menggunakan tombol. Pagar yang dirancang juga menggunakan mikrokontroler Arduino Uno, 1 daun pintu pagar, dan 1 buah motor DC. Cara kerja dari rancangan pintu pagar pada jurnal tersebut yaitu input dari ketiga perangkat keras tersebut akan diterima oleh mikrokontroler yang nanti akan mengontrol arah putaran motor DC tersebut menyebabkan pintu pagar melakukan gerakan menutup dan membuka.

Alat yang dirancang adalah sebuah sistem pengontrolan pagar besi rumah menggunakan smartphone android dari jarak jauh menggunakan komunikasi bluetooth. Pada smartphone pengguna akan menjalankan sebuah aplikasi program yang dapat mengirimkan perintah kontrol pada mikrokontroler yang dipasangkan pada pintu pagar. Perintah yang diberikan berupa buka atau tutup pagar, membuka kunci pagar, mengunci pagar, dan mengkoneksikan bluetooth.

Perancangan alat akan menggunakan sebuah mikrokontroler Arduino yang berisikan program untuk menerima, mengolah, dan menjalankan perintah yang diberikan oleh program pada android. Pada mikrokontroler arduino digunakan modul bluetooth sebagai alat komunikasi antara mikrokontroler dengan Android, sehingga perintah dapat diterima dalam bentuk kiriman data untuk program Arduino.

Pintu pagar rumah rancangan ini dilengkapi sebuah sensor obyek yang digunakan sebagai pendeteksi obyek yang sedang melewati pagar. Fungsi sensor obyek pada sistem ini yaitu menahan pergerakan pintu pagar ketika kendaraan atau seseorang sedang melewati pintu pagar, sehingga pintu pagar tidak dapat ditutup. 
Sistem pintu pagar jarak jauh ini juga dilengkapi dengan modul pengunci yang dapat menahan pergerakan pagar dan juga sebagai sistem keamanan. Cara kerja modul kunci yaitu ketika telah diberikan perintah "kunci" maka aksi modul kunci akan melakukan pembatasan pergerakan pintu pagar. Perintah buka kunci harus terlebih dahulu diberikan sebelum perintah buka pagar diberikan.

Perbandingan hasil survei dengan sistem yang akan dirancang dari hasil survei-survei yang telah dilakukan dengan mengamat cara kerja otomasi pintu pagar.

\section{DESKRIPSI KONSEP}

Sistem kontrol pintu pagar yang dirancang akan memerlukan input perintah dari smartphone Android menggunakan koneksi bluetooth untuk melakukan gerakan membuka/menutup pintu pagar, serta menutup kunci/membuka kunci pagar. Fungsi-fungsi tersebut dapat dilakukan dengan memasang beberapa modul rangkaian elektronika berikut, yaitu modul relay untuk kontrol motor DC, modul tombol manual manual, modul sensor obyek, modul pengunci, modul catu daya, modul pemroses, modul bluetooth, dan dilengkapi dengan panel LCD.

Modul mikrokontroler digunakan sebagai pemrosesan perintah dan penghubung dari smartphone Android dengan modul lain yang akan melengkapi pengontrolan sistem perancangan ini. Program yang didesain pada mikrokontroler dapat menerima input dari receiver bluetooth dan menjalankan perintah dari smartphone Android. Komunikasi antara mikrokontroler Arduino dengan smartphone Android menggunakan modul bluetooth.

Modul bluetooth akan dipasangkan pada mikrokontroler Arduino sebagai receiver dan transmitter, sehingga dapat menerima perintah serta dapat mengirimkan status kontrol. Perintah yang dikirim dapat berupa buka pagar, tutup pagar, kunci pagar, dan buka kunci pagar.

Pada saat perintah untuk menutup/membuka pintu pagar diberikan, maka penggerakan pintu pagar tersebut diatur oleh modul relay yang terhubung dengan motor direct current (DC). Modul relay dikontrol oleh program mikrokontroler sehingga dapat diatur arah putaran. Metode pengontrol relay pada modul relay menggunakan metode on atau off. Metode ini dirancang dengan prinsip pada saat mikrokontroler Arduino menerima perintah menutup/membuka, maka pin output pengontrol modul relay pagar akan mengatur relay yang akan menjadi menghubung sumber tegangan dengan ground untuk motor dc sehingga terjadi perubahan arah putar motor.

Sistem kontrol ini juga memiliki modul sensor obyek yang digunakan untuk mendeteksi obyek yang ingin melintas ketika pagar diberikan perintah menutup. Pada saat ada obyek didepan sensor obyek maka pagar tidak dapat memproses perintah menuutup pintu pagar sampai obyek tersebut bergerak menjauhi sensor obyek. Komponen sensor obyek yang digunakan yaitu ultrasonic sensor. Dengan adanya modul sensor maka penutupan pintu pagar akan lebih aman bagi penggunanya dan mengurangi kerusakan akibat benturan pintu pagar dengan obyek yang melintas.

Sistem ini juga dilengkapi dengan modul pengunci menggunakan komponen kunci servo yang dapat dihubungkan langsung dengan mikrokontroler. Rancangan prinsip kerja yang akan digunakan yaitu program pada mikrontroler akan memberikan input derajat putaran yang harus dilakukan oleh kunci servo dan mengunci pergerakan pagar pada saat pintu pagar tertutup.

Modul tombol manual akan dihubungkan menggunakan kabel sebagai kontrol pintu pagar membuka/menutup dan kontrol kunci. Tombol ini dapat digunakan ketika pengguna sistem kontrol tidak memiliki smartphone atau tidak dapat menguhubungkan koneksi bluetooth.

Catu daya yang digunakan adalah 2 buah catu daya modular menghasilkan 12VDC dan sebuah down converter $5 \mathrm{~V}$ DC. Catu daya yang satu digunakan untuk sumber tegangan motor DC, serta catu daya yang lain untuk sumber tegangan modul pemroses dan down converter. Apa bila terjadi mati listrik pada maka pagar tetap dapat digerakan secara manual yaitu melepas lintasan gear rack dari pintu pagar sehingga dapat didorong ke kiri/kanan. Diagram blok dari rancangan sistem ini dapat dilihat pada Gambar 2. 


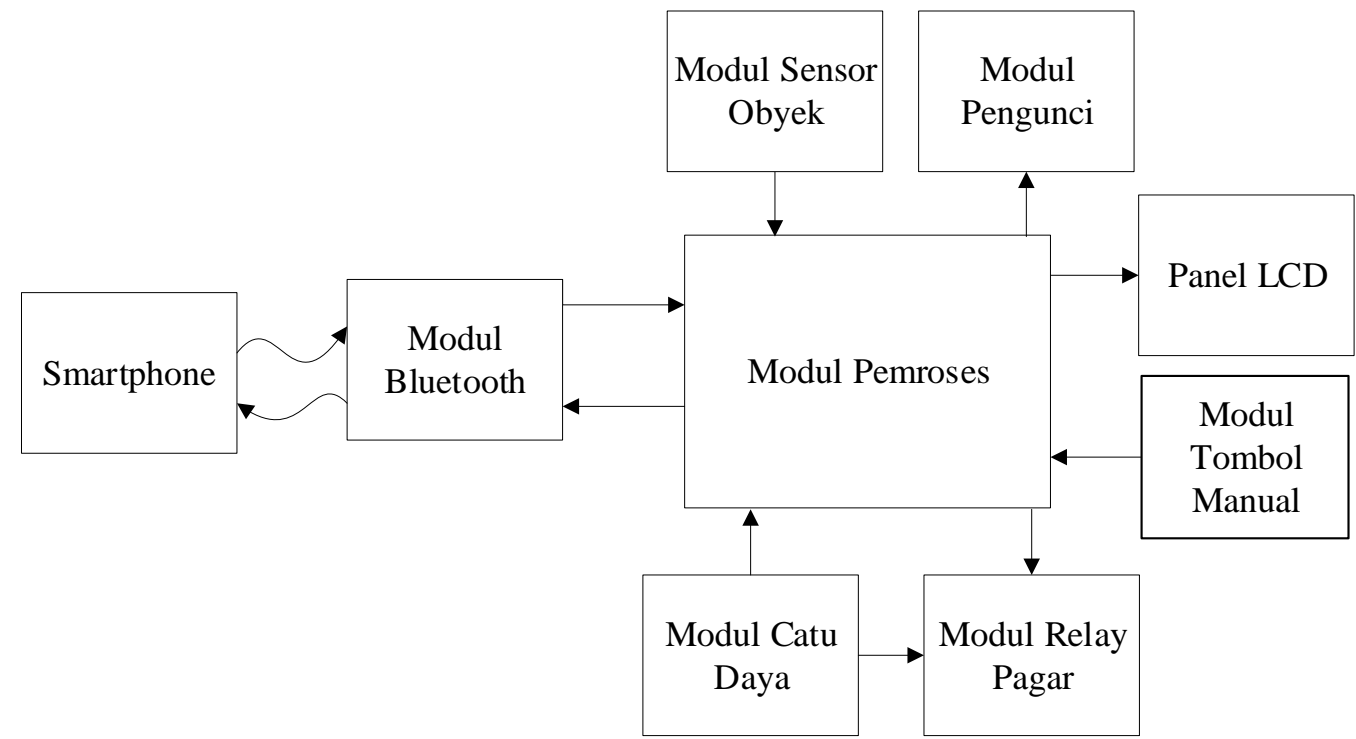

- Gambar 2. Diagram Blok Perancangan Sistem Kontrol Pintu Pagar Rumah Jarak Jauh Berbasis Arduino dengan Bluetooth pada Smarphone Android

\section{BLUETOOTH}

Bluetooth adalah teknologi yang memungkinkan dua perangkat yang kompatibel, seperti telepon dan personal computer (PC) untuk berkomunikasi tanpa kabel dan tidak memerlukan koneksi saluran yang terlihat. Teknologi ini memberikan perubahan yang Bluetooth sesungguhnya merupakan spesifikasi industri untuk jaringan wilayah pribadi nirkabel (WPAN)[1]. Bluetooth beroperasi dengan frekuensi 2,4Ghz dengan menggunakan sebuah frequency hopping tranceiver yang mampu menyediakan layanan komunikasi data dan suara secara langsung antara host-host Bluetooth dengan jarak terbatas. Kelemahan teknologi ini adalah jangkauannya yang pendek dan kemampuan transfer data yang rendah.

Pada dasarnya Bluetooth diciptakan bukan hanya menggantikan atau menghilangkan penggunaan kabel didalam pertukaran informasi, tetapi juga mampu memberikan fitur teknologi mobile wireless dengan biaya yang relatif rendah, dan konsumsi daya yang rendah. Smartphone yang kita gunakan saat ini juga memiliki koneksi Bluetooth untuk pengiriman data file, mendengarkan lagu secara wireless, dan sebagai sarana komunikasi untuk developer aplikasi seperti yang dilakukan pada perancangan ini. Aplikasi perncangan yang diprogram memerlukan koneksi Bluetooth sebagai saran pengiriman data untuk mengirimkan perintah. Koneksi Bluetooth juga digunakan pada mikrokontroler yang akan menerima perintah dan memprosesnya untuk melakukan kontrol. Gambar koneksi Bluetooth menghubungkan mikrokontroler dengan smartphone dapat dilihat pada Gambar 3.
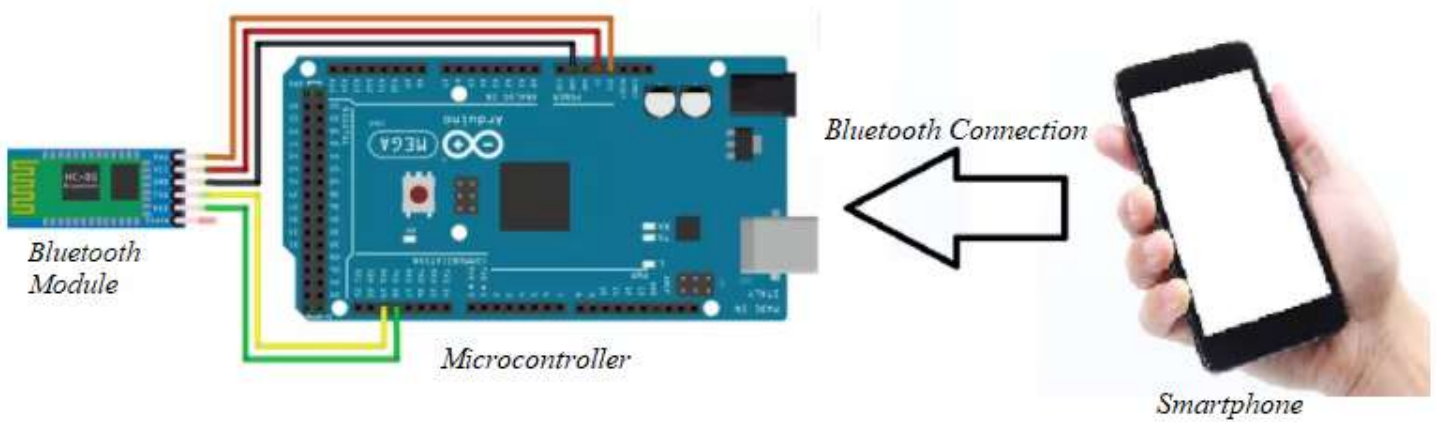

- Gambar 3. Koneksi Bluetooth Menghubungkan Mikrokontroler dengan Smartphone

\section{MODUL MIKROKONTROLER ARDUINO MEGA 2560}

Mikrokontroler adalah sebuah chip yang minimal terdiri dari Central Processing Unit (CPU), non-volatile memory, volatile memory, timer dan unit pengontrol input/output (I/O)[4]. selain komponen-komponen tersebut, biasanya juga terdiri dari komponen untuk komunikasi serial, pengontrolan interrupt, dan unit pengontrol I/O analog. 
Mikrokontroler merupakan perangkat keras yang digunakan untuk mengontrol seluruh atau sebagian perangkat keras lainnya dalam kerja suatu alat atau purwarupa alat. Penggunaan mikrokontroler harus terlebih dahulu diprogram secara spesifik untuk menentukan cara kerjanya.

Mikrokontroler memiliki banyak jenis dimulai dari AVR, PIC, ST Microelectronics, dan masih banyak lagi. Pengembangan mikrontroler AVR dilakukan pada sebuah mikrokontroler Arduino yaitu sebuah mikrokontroler yang menggunakan mikroprosesor ATmega.

Mikorkontroler yang penulis gunakan untuk menjalankan program perancangan sistem ini yaitu Arduino Mega 2560 yang menggunakan mikrokontroler ATmega2560 dan memiliki 54 pin digital I/O (dimana 15 buah pin dapat digunakan untuk pulse width modulation output), dan 16 pin analog input, 4 UARTs (serial port hardware), sebuah $16 \mathrm{MHz}$ osilator kristal, slot USB (Universal Serial Bus), power jack, ICSP header[5].

Penggunaan Arduino Mega digunakan sebagai modul pemroses pada perancangan alat ini. Arduino Mega memungkinkan perancangan alat dapat dilengkapi dengan sensor serta hardware pelengkap lainnya. Arduino Mega merupakan sebuah mikrokontroler yang memakai IC mikrokontroler ATMega 2560. Arduino Mega digunakan karena memiliki GPIO yang banyak terdiri dari 54 pin digital I/O dan 16 pin analog input.

Fitur-fitur yang utama yang dimiliki antara lain adalah fitur Analog to Digital Converter (ADC), komunikasi serial berupa Universal Synchronous Asynchronous Receiver and Transmitter (USART), timer, Static Random Access Memory (SRAM) sebesar 8 Kilo bytes, dan Flash Memory sebesar 256 Kilo bytes. Arduino Mega juga memiliki 4 buah port komunikasi serial yang digunakan untuk komunikasi serial dengan sensor GPS dan modul WiFi. Gambar bentuk fisik Arduino Mega 2560 dapat dilihat pada Gambar 4.

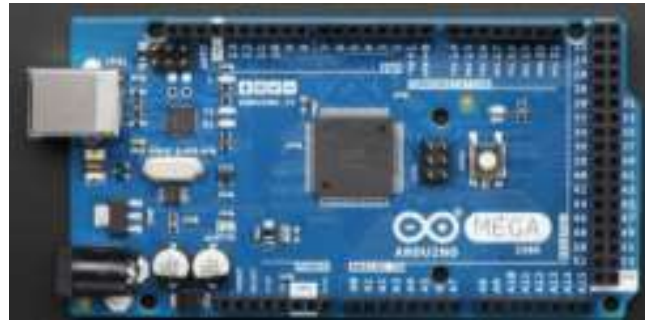

- Gambar 4. Bentuk Fisik Arduino Mega 2560

\section{CATU DAYA}

Penggunaan catu daya pada perancangan ini bertujuan untuk memberikan tegangan listrik untuk motor DC, modul pemroses, dan modul pengunci. Catu daya merupakan sebuah sumber tegangan listrik bagi berbagai jenis perangkat dimulai dari komponen kecil, hingga mesin-mesin besar. komponen dasar yang digunakan untuk rangkaian yang lebih sederhana adalah transformator, penyearah (dioda), resistor, kapasitor, dan inductor.

Trafo yang dimiliki catu daya menggunakan jenis step down, dan memerlukan input tegangan listrik alternate current (AC) sebesar 220V. Perancangan ini menggunakan 2 buah catu daya dimana 1 catu daya menghasilkan tegangan direct current (DC) sebesar 12V dengan kapasitas arus maksimal 10A untuk sumber tenaga motor DC, dan tegangan catu daya yang lain menghasilkan tegangan $12 \mathrm{~V}$ dengan kapasitas arus 3,2 A.

Penggunaan catu daya dalam perancangan sistem untuk memberikan tegangan pada modul pemroses mikrokontroler Arduino Mega 2560, motor DC melewati relay, dan modul pengunci. Gambar bentuk fisik modul catu daya dapat dilihat pada Gambar 5.

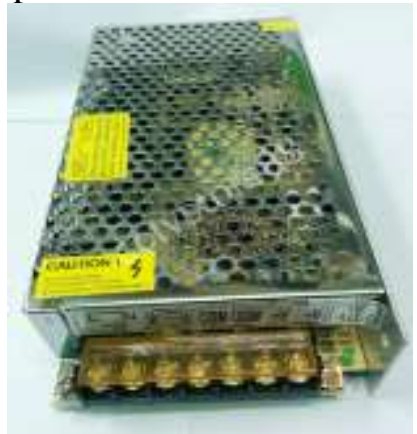

- Gambar 5. Bentuk Fisik Catu Daya 


\section{MODUL SENSOR OBYEK}

Modul sensor obyek pada perancangan ini menggunakan sebuah sensor ultrasonik US-100. Bunyi ultrasonik yang dihasilkan dari modul sensor ini adalah $40 \mathrm{kHz}$. Pada sensor ultrasonik, gelombang ultrasonik dibangkitkan melalui sebuah alat yang disebut dengan piezoelektrik dengan frekuensi tertentu. Gambar bentuk fisik sensor Ultrasonik US-100 dapat dilihat pada Gambar 6.

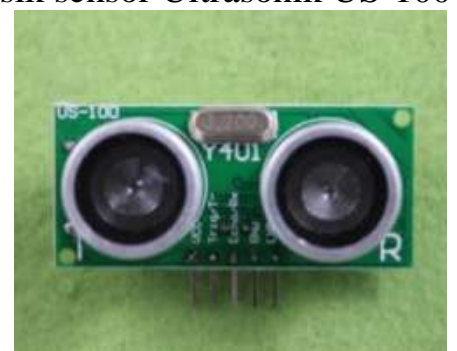

- Gambar 6. Bentuk Fisik Sensor Ultrasonik US-100

Piezoelektrik ini akan menghasilkan gelombang ultrasonik ketika sebuah osilator diterapkan pada benda tersebut. Secara umum, alat ini akan menembakkan gelombang ultrasonik menuju suatu area atau suatu target. Setelah gelombang menyentuh permukaan target, maka target akan memantulkan kembali gelombang tersebut. Gelombang pantulan dari target akan ditangkap oleh sensor, kemudian sensor menghitung selisih antara waktu pengiriman gelombang dan waktu gelombang pantul diterima.

\section{MODUL RELAY}

Fungsi kontrol arah putar motor DC akan menggunakan 2 buah modul relay yang akan dikontrol oleh modul program pemroses pada Arduino Mega. Modul relay memiliki komponen relay yang bekerja seperti sebuah switch dengan hal yang membedakannya yaitu cara pengaktifannya menggunakan sebuah coil yang mengatur kontrol switching tersebut.

Dalam sebuah relay terdapat bagian COM yaitu bagian kaki pada relay yang akan terhubung langsung dengan normally closed (NC), dan ketika coil mendapatkan tegangan maka COM akan terhubung dengan kaki normally open (NO) dan melepaskan hubungan dari NC. Coil akan aktif bila diberi tegangan listrik DC sedangkan hubungan antara COM dengan NC maupun NO dapat berupa listrik AC atau DC.

Penggunaan modul relay ini biasanya digunakan untuk melakukan kontrol suatu alat dengan tegangan DC maupun AC. Pada perancangan sistem ini relay yang digunakan adalah 1 channel relay modul dengan pilihan aktif high pada coilnya. Cara kerja modul relay pada perancangan sistem ini yaitu relay akan mengatur tegangan $\mathrm{V}+$ dan $\mathrm{V}$ - secara bergantian untuk merubah arah putaran pada motor DC. Gambar bentuk fisik modul relay dapat dilihat pada Gambar 6.

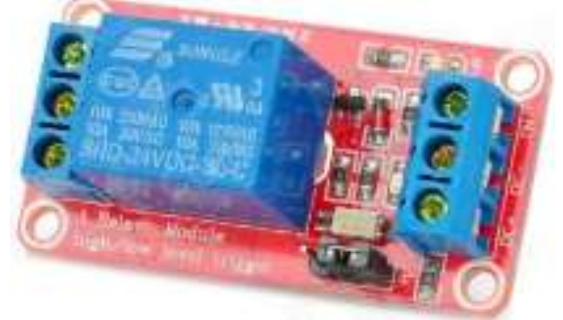

- Gambar 6. Bentuk Fisik Modul Relay

\section{MODUL PENGUNCI}

Modul pengunci perancangan ini menggunakan sebuah motor servo dengan jenis putaran diskrit yang kemudian akan dipasangkan pada sebuah mekanisme bar pengunci. Motor servo pada modul memiliki pin 5v, pin signal, dan pin ground, yang dioperasikan dengan memberikan input sinyal PWM pada pin signal. Sinyal PWM tersebut merupakan data dalam nilai derajat putaran yang harus dituju oleh motor servo. Gambar bentuk fisik modul pengunci dapat dilihat pada Gambar 7. 


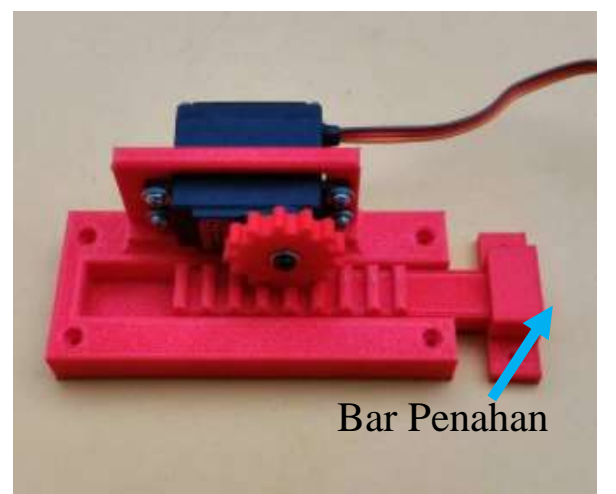

- Gambar 7. Bentuk Fisik Modul Pengunci

Pada perancangan, modul pengunci berguna untuk menahan gerakan pagar dengan memajukan bar penahan pada modul ketika sudah diberi perintah mengunci pagar, serta dapat membuka kunci dengan menarik bar penahan ketika diberi perintah buka kunci. Pada saat diberikan perintah mengunci atau membuka kunci maka mikrokontroler akan memproses perintah dan memberikan data berupa derajat pada outpout GPIO PWM yang terhubung dengan pin signal modul pengunci.

\section{TO DC DOWN CONVERTER 5 VOLT}

Sebuah down converter digunakan untuk menghubungkan catu daya dengan modul pengunci dan menurunkan tegangan output catu daya $12 \mathrm{~V}$ menjadi $5 \mathrm{~V}$ dengan maksimum arus yg dihasilkan $3 \mathrm{~A}$. Gambar bentuk fisik $D C$ to DC down converter dapat dilihat pada Gambar 8.

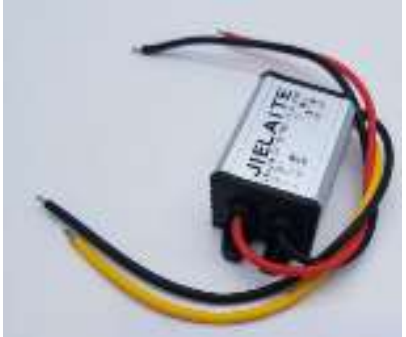

- Gambar 8. Bentuk Fisik DC to DC Down Converter

Down converter ini digunakan untuk menghasilkan tegangan yang stabil untuk motor servo pada modul pengunci. Down converter akan dihubungkan dari pin $+5 \mathrm{v}$ ke pin $5 \mathrm{v}$ modul pengunci, dan pin GND menuju pin GND modul pengunci.

\section{MOTOR DC 12 VOLT}

Pergerakan pagar akan menggunakan sebuah motor de dengan jenis putaran continuous yang dipasang kepada sebuah model pagar yang telah dirancang khusus untuk sistem ini. Motor dc yang digunakan menggunakan tegangan $12 \mathrm{~V}$ dan menghasilkan torsi sebesar $11 \mathrm{Nm}$ dengan kecepatan $70 \mathrm{rpm}$. Gambar bentuk fisik motor de dapat dilihat pada Gambar 9.

Sebuah motor DC dapat dibalikan arah putaran bila polarisasi atau arus masuk diberikan pada kutub yang berlawanan. Bila pada suatu input diberikan V+ dan input yang lainnya diberikan V- serta melakukan arah putaran ke kanan. Jika b kita balikan input tersebut maka putaran motor dc akan menuju arah sebaliknya. Pada sistem ini pengatur arah putaran motor DC akan menggunakan 2 buah modul relay yang akan diproses oleh modul program pemroses. Putaran yang dilakukan bergantung pada gerakan membuka dan menutup pagar.

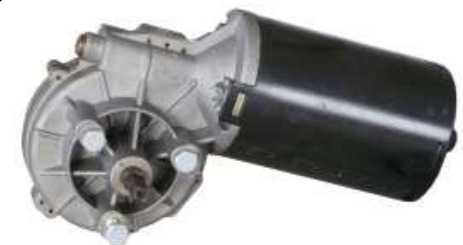

- Gambar 9. Bentuk Fisik Motor DC

\section{PANEL LIQUID CRYSTAL DISPLAY 16X2}

Liquid Crystal Display (LCD) adalah suatu jenis media tampil yang menggunakan kristal cair sebagai penampil utama. LCD sudah digunakan di berbagai bidang misalnya alat-alat elektronik seperti televisi, kalkulator, atau pun layar komputer. Fungsi tampilan status pagar akan menggunakan sebuah 
panel LCD 16x2 yang dapat menampilkan huruf dan angka pada 16 kolom dan 2 baris tampilan LCD. Agar memudahkan pemrograman, panel LCD akan menggunakan sebuah komponen tambahan pada LCD yaitu I2C (Inter-Intergrated Circuit) yang mengubah kontrol paralel LCD menjadi kontrol serial. Pada I2C terdapat 4 buah pin yaitu pin seria data, pin serial clock, VCC, dan GND. Detail dan fiturfitur secara lengkap dari LCD panel dapat dilihat pada Lampiran 8.

Arduino Mega 2560 sudah mendukung protokol I2C, dimana terdapat pin serial data (SDA) dan pin serial clock (SCL). Library pada program pemroses yang digunakan akan berupa LiquidCrystal_I2C.h. Gambar bentuk fisik panel LCD dengan I2C dapat dilihat pada Gambar 10.

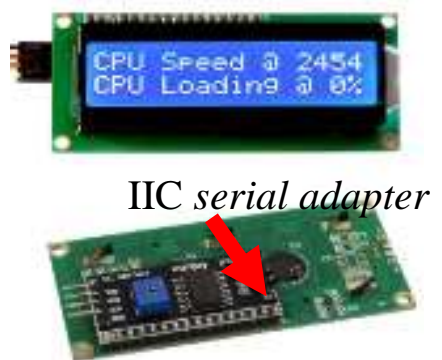

- Gambar 10. Bentuk Fisik Panel LCD dengan I2C

\section{MODUL PROGRAM ANDROID}

Untuk mengendalikan pintu pagar dari jarak jauh akan digunakan sebuah smartphone dengan koneksi Bluetooth yang menggunakan Android sebagai sistem operasinya. Perancangan modul program menggunakan MIT App Inventor yaitu sebuah website untuk menghasilkan program berbasis Android tanpa bahasa pemrograman Java. Website ini mampu menyusun tampilan program dan menggunakan bahasa pemograman seperti $\mathrm{C}++$ yang nanti dapat diunduh dan menginstal program tersebut dalam smartphone.

Penyusunan modul program Android ini dilakukan dengan memulai penyusunan tampilan yang diinginkan. Pada perancangan ini diperlukan tampilan tombol koneksi Bluetooth, tombol buka, tombol tutup, tombol kunci pagar, dan tombol buka kunci pagar, serta sebuah box status program ketika sudah terhubung lalu menampilkan status tombol yg ditekan. Tampilan program pada smartphone Anroid dapat dilihat pada Gambar 11.

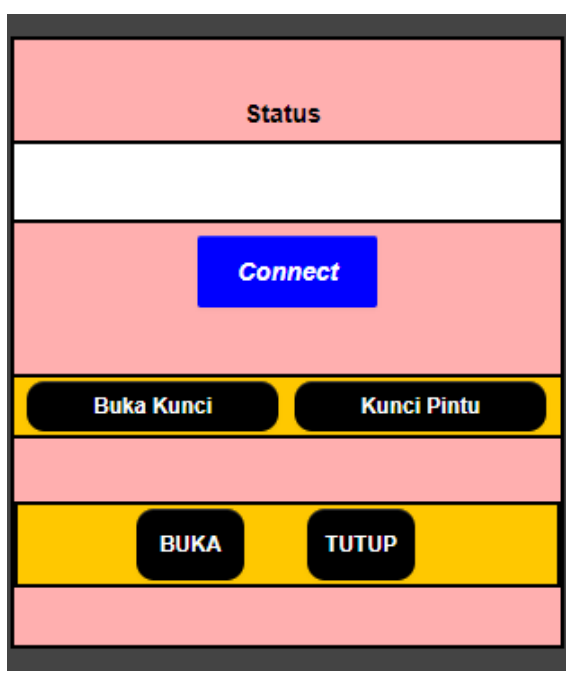

- Gambar 11.Tampilan Program pada Smartphone Android

Program akan berjalan pertama kali menghasilkan tampilan seperti pada Gambar 3.29, bila Bluetooth pada smartphone belum menyala maka tampilan status akan meminta pengguna untuk menyalakan Bluetooth smartphone. Bila Bluetooth sudah menyala maka koneksi dapat dilakukan dengan menekan tombol "connect" dimana akan menampilkan list Bluetooth yang aktif. Bila koneksi dengan modul Bluetooth alat berhasil maka pengontrolan pagar dapat dilakukan. Tombol "buka" akan mengirimkan data string "A" yang nanti akan diterima oleh modul Bluetooth dan diteruskan menuju modul program pemroses, lalu mengontrol modul relay untuk menggerakan motor DC untuk menggerakan pagar. 


\section{PENGUJIAN DAN ANALISIS KESELURUHAN SISTEM}

Pengujian dan analisis sistem dilakukan untuk mengetahui sistem yang dirancang telah berfungsi dengan baik. Pengujian dilakukan dengan menghubungkan seluruh modul yang dipakai, baik yang dirancang maupun yang tidak dirancang, serta melakukan pengamatan respon model pagar.

Modul pemroses akan disambungkan dengan modul sensor obyek, modul pengunci, modul relay, modul tombol manual, modul catu daya, dan modul Bluetooth. Selanjutnya, modul relay akan disambungkan dengan motor DC dan catu daya 12V 10A pada modul catu daya. Motor servo pada modul pengunci akan disambungkan dengan down converter $5 \mathrm{~V}$ 1A pada modul catu daya. Dengan komunikasi Bluetooth pada modul Bluetooth akan menghubungkan modul program Android pada smartphone. Lalu, modul program pemroses akan diunduh kedalam modul pemroses untuk menjalankan fungsi kesatuan alat. Tabel pengujian sistem keseluruhan dapat dilihat pada Tabel 1.

-Tabel 1. Tabel Pengujian Sistem Keseluruhan

\begin{tabular}{|c|c|c|}
\hline $\begin{array}{l}\text { Pengujian } \\
\text { ke- }\end{array}$ & Kondisi yang Diberikan & Hasil \\
\hline 1 & $\begin{array}{l}\text { Menekan tombol connect pada layar } \\
\text { smartphone menggunakan modul } \\
\text { program Android }\end{array}$ & Bluetooth berhasil terhubung \\
\hline 2 & $\begin{array}{l}\text { Menekan tombol buka pada layar } \\
\text { smartphone menggunakan modul } \\
\text { program Android }\end{array}$ & Model pintu pagar terbuka \\
\hline 4 & $\begin{array}{l}\text { Menekan tombol tutup pada layar } \\
\text { smartphone menggunakan modul } \\
\text { program Android }\end{array}$ & Modul pintu pagar menutup \\
\hline 4 & $\begin{array}{l}\text { Menekan tombol kunci pintu pada } \\
\text { layar smartphone menggunakan } \\
\text { modul program Android }\end{array}$ & $\begin{array}{l}\text { Bar pada modul pengunci bergerak maju, menahan gerakan } \\
\text { pintu pagar }\end{array}$ \\
\hline 5 & $\begin{array}{l}\text { Menekan tombol buka kunci pada } \\
\text { layar smartphone menggunakan } \\
\text { modul program Android }\end{array}$ & $\begin{array}{l}\text { Bar modul pengunci bergerak mundur, melepaskan gerakan } \\
\text { pintu pagar }\end{array}$ \\
\hline 6 & $\begin{array}{l}\text { Menekan tombol tutup pada layar } \\
\text { smartphone menggunakan modul } \\
\text { program Android, dan menghalangi } \\
\text { modul sensor obyek }\end{array}$ & Model pintu pagar tidak dapat menutup \\
\hline 7 & $\begin{array}{l}\text { Menekan tombol buka pada layar } \\
\text { smartphone menggunakan modul } \\
\text { program Android dan menghalangi } \\
\text { modul sensor obyek }\end{array}$ & Model pintu pagar menutup \\
\hline 8 & $\begin{array}{l}\text { Menekan tombol buka pada modul } \\
\text { tombol manual }\end{array}$ & Model pintu pagar terbuka \\
\hline 9 & $\begin{array}{l}\text { Menekan tombol tutup pada modul } \\
\text { tombol manual }\end{array}$ & Model pintu pagar tertutup \\
\hline 10 & $\begin{array}{l}\text { Menekan tombol buka kunci pada } \\
\text { modul tombol manual }\end{array}$ & $\begin{array}{l}\text { Bar modul pengunci bergerak mundur, melepaskan gerakan } \\
\text { pintu pagar }\end{array}$ \\
\hline 11 & $\begin{array}{l}\text { Menekan tombol kunci pintu pada } \\
\text { modul tombol manual }\end{array}$ & $\begin{array}{l}\text { Bar pada modul pengunci bergerak maju, menahan gerakan } \\
\text { pintu pagar }\end{array}$ \\
\hline 12 & $\begin{array}{l}\text { Menekan tombol buka pada modul } \\
\text { tombol manual, dengan } \\
\text { menghalangi modul sensor obyek }\end{array}$ & Model pintu pagar terbuka \\
\hline 13 & $\begin{array}{l}\text { Menekan tombol tutup pada modul } \\
\text { tombol manual, dengan } \\
\text { menghalangi modul sensor obyek }\end{array}$ & Model pintu agar tidak dapat menutup \\
\hline
\end{tabular}




\section{KESIMPULAN DAN SARAN}

Berdasarkan hasil pengujian sistem, dapat diberikan beberapa kesimpulan dan saran yaitu :

Kesimpulan yang dapat diambil dari perancangan sistem kontrol ini yaitu perancangan sistem kontrol pintu pagar rumah berbasis Arduino dengan koneksi nirkabel Bluetooth pada smartphone Android dapat mengontrol buka atau tutup model pintu pagar rumah, sertadapat mengunci atau membuka kunci model pintu pagar rumah menggunakan smartphone menggunakan koneksi Bluetooth. Sebagai saran adalah memberikan tambahan sebuah modul mekanisme rem otomatis untuk kejadian ketika pintu pagar telah bergerak untuk menutup dan ada obyek yang ingin melintas keluar dan masuk pintu pagar agar tidak saling menabrak dan terdapat sebuah modul pendeteksi bahaya seperti contoh pendeteksi kemalingan, dan modul tersebut mengirimkan gambar keadaan pintu pagar rumah ke smartphone Android.

\section{DAFTAR PUSTAKA}

[1] Susaptoyono. Yogyo, Bluetooth, Yogyakarta: Cv. Andi, 2012

[2] EMS Team, Android: All in One, Jakarta: PT. Elex Media Komputindo, 2013

[3] Felker. Donn, Android Application Development for Dummies, Hoboken, NJ: Wiley Publishing, Inc., 2011.

[4] J. Iovine, PIC robotics. New York: McGraw-Hill, 2004, pp. 1.

[5] Arduino, Arduino Mega 2560, https://store.arduino.cc/usa/arduino-mega-2560-rev3 (diakses pada tanggal 6 April 2018)

[6] R. Syahban, Arduino \& Proteus: Simulasi dan Praktik, Bandung: Penerbit INFORMATIKA Bandung, 2016 